\title{
TRANSIENT STATE CHARACTERIZATION OF ASYNCHRONOUS MOTORS IN MODERN LOW-VOLTAGE ELECTRIC INSTALLATIONS
}

\author{
Emil CAZACU, Valentin IONIŢĂ, Lucian PETRESCU \\ University POLITEHNICA of Bucharest, Romania, Faculty of Electrical Engineering, \\ 313, Splaiul Independentei, 060042, district 6, Bucharest ROMANIA, \\ E-mail: emil.cazacu@upb.ro,valentin.ionita@upb.ro, lucian.petrescu@upb.ro
}

\begin{abstract}
Low-voltage asynchronous motor is the most common load used in any industrial electric facility. Due to their robustness and reliability, the induction motors have a very large application spectrum and are to be found in a variety of power units. It is assumed that over $70 \%$ of total energy used in any electric utility is dedicated to the electric motor drive systems. The paper quantitatively studies the transient state of such motors, which occurs at their start-up. The waveforms characteristics of these inrush currents are predetermined mainly by solving the associated differential equations that describe the dynamic phenomena at their start-up. An experimental investigation on an induction motor of $4 \mathrm{~kW}$ is also carried out. Supplementary, different solutions for the energising of these low-voltage motors are presented highlighting their performances and limits. These methods are critically rated according to their mitigation ability of the power quality issues associated with the energizing process.
\end{abstract}

Keywords: asynchronous motor, inrush current, transient state

\section{INTRODUCTION}

Three phase asynchronous motor is a particular receptor whose normal regime (rated state) is not established immediately after connecting to the network, but is preceded by the so-called start-up mode [1-6]. In this particular transient state, the basic electrical and mechanical machine parameters changes as the rotor accelerates. The inrush currents associated with the motor connection to the network have values that could exceed the motor rated currents and exhibit special distorted waveforms [7-13]. These features of these inrush currents additionally stress up both the motor by increasing the losses within the motor and the supply network by adversely affecting the other loads or receptacles, connected at the common coupling point [14-17]. This paper is going to qualitatively and quantitatively investigate the starting process when the machine is not or light loaded. The computation method bases on the analytical solution of the differential equations that model the starting phenomena, requiring the machine rated data and its dynamical characteristics. The main parameters for analysing the electromechanical behaviour of the machine during this transient state are the motor starting time and the machine's rotor slip variation. The inrush current investigations are also experimentally performed on a $4 \mathrm{~kW}$ induction motor in light load conditions. Different modern solutions that could conveniently overcome the main induction motor starting issues are also analysed in terms of their performances i.e. the generated harmonics currents and additional losses.

\section{THE MOTOR TRANSIENT STATE AT THE STARTING PROCESS}

The starting up process of an induction motor is characterized by time variation of the motor rotational speed and absorbed electric current after the connection of the machine to the supply network. Accordingly, in order to mathematically characterise the motor starting behaviour, one should solve the associated differential equation that models the dynamic process. Thus, considering a not loaded motor, the motor starting time $t_{s}$ can be derived [1-5]:

$$
J \frac{\mathrm{d} \Omega}{\mathrm{d} t}=M_{a}=M-M_{r} \Rightarrow t_{s}=J \int_{0}^{\Omega} \frac{\mathrm{d} \Omega}{M-M_{r}}
$$

where $J$ is the moment of inertia of all masses put into motion (which includes the working machine), $\Omega$ is the momentary angular speed of the rotor:

$$
\Omega=2 \pi n=2 \pi n_{1}(1-s)=\Omega_{1}(1-s)
$$

with $s=\frac{n_{1}-n}{n_{1}}$, the motor slip, usually indicated in terms of the rotational magnetic field and rotor speeds $n_{1}$ and $n$ respectively. Supplementary, $M_{a}$ represents the accelerator torque, which is defined as the difference between active torque developed by the motor $M$, and the load torque $M_{r}$.

Considering the resisting (load) torque zero $\left(M_{r}=0\right)$, the starting time of the motor can be analytically predicted by considering the Klöss relationship [16-20]:

$$
\begin{aligned}
& J \frac{\mathrm{d} \Omega}{\mathrm{d} t}=M_{a}=M=\frac{2 M_{m}}{s / s_{m}+s_{m} / s} \Rightarrow \\
& \Rightarrow t_{s}=\frac{T_{m}}{2}\left(\frac{1-s^{2}}{2 s_{m}}+s_{m} \ln \frac{1}{s}\right)
\end{aligned}
$$

where $T_{m}=\frac{J \Omega_{1}}{M_{m}}$ is called no load starting up electromechanical time constant and lies in the interval of 
$1 \div 2$ seconds [1-8] and $s_{m}$ is he maximum or critical sleep of the induction motor having the usual values between $0.1 \div 0.5$ (a specific feature of the induction motor natural mechanical characteristic).

Assuming now a loaded motor with a constant resisting torque $\left(M_{r} \neq 0\right)$, its starting time can be also analytically evaluated:

$$
\begin{aligned}
& t_{p}=T_{m} \int_{s}^{1}\left(\frac{s^{2}+s_{m}^{2}}{-\alpha s^{2}+2 s_{m} s-\alpha s_{m}^{2}}\right) \mathrm{d} s= \\
& =\frac{T_{m}}{\alpha} \int_{s}^{1}\left[\frac{s^{2}+s_{m}^{2}}{\left(s-s_{1}\right)\left(s-s_{2}\right)}\right] \mathrm{d} s,
\end{aligned}
$$

where: $\quad \alpha=\frac{M_{r}}{M_{m}}, \quad$ and: $\quad s_{1}=\frac{s_{m}}{\alpha}\left(1-\sqrt{1-\alpha^{2}}\right)$, $s_{2}=\frac{s_{m}}{\alpha}\left(1+\sqrt{1-\alpha^{2}}\right)$, with $s_{1}<s_{m}<1<s_{2}$.

The slips $s_{1}$ and $s_{2}$ results from the intersection of the mechanical characteristics of the motor $M=M(s)$ and the working machinery $M=M_{r}$. It can be demonstrated [18-26] that the first operating point, characterized by the slip $s_{1}$, is a stable one, imposing the steady state of the machine.

The rotor slip time variation for different values of parameters $\alpha$ and for a critical slip $s_{m}=0.15$ is presented in Figure 1.

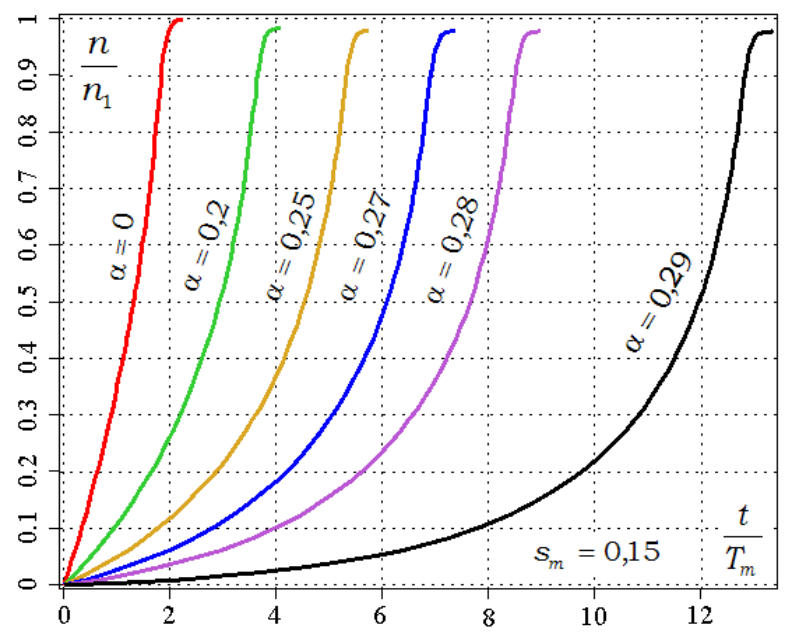

Figure 1. The rotor slip time variation for different values of parameters $\alpha$ and for a critical slip $s_{m}=0,15$.

Rotor current variation during start-up process can be estimated by equalizing the amount of electromagnetic power with the losses in the rotor equivalent resistance:

$$
P_{e}=M \cdot \Omega_{1}=3 \frac{R_{2}^{\prime} I_{2}^{\prime 2}}{s}
$$

with $R_{2}^{\prime}, I_{2}^{\prime}$ the rotor resistance and windings current).
If one neglects the no load current, the current absorbed by the stator during the start-up equals the value of the rotor current. Using the Klöss relation, the stator current induction motor current becomes $[13,14]$ :

$$
\begin{aligned}
I^{2} & =\frac{2 M_{m} \Omega_{1}}{3 R_{2}^{\prime}} \frac{s_{m} \cdot s^{2}}{s^{2}+s_{m}^{2}} \\
I_{p}^{2} & =\frac{2 M_{m} \Omega_{1}}{3 R_{2}^{\prime}} \frac{s_{m}}{1+s_{m}^{2}}=\frac{M_{p} \Omega_{1}}{3 R_{2}^{\prime}}, \quad(s=1) .
\end{aligned}
$$

Therefore, the current variation absorbed by the motor during the start-up process is described by the relation:

$$
I^{2}=I_{p}^{2}\left(1+s_{m}^{2}\right) \frac{s^{2}}{s^{2}+s_{m}^{2}}
$$

Figure 2-a depicts the variation curve of the induction motor inrush current as a function of the rotational speed at different critical slips. One can notice that for large sleeps, the inrush current varies unessential and, when the sleeps reaches the critical values, the currents increases significantly. Finally, the inrush current is practically cancels for a zero sleep. The time variation of the starting current is shown in Figure 2-b for different values of parameter $\alpha$ and for the critical slip of $s_{m}=0.15$. One may note that the value of current absorbed by the motor tends asymptotically towards a stabilized value, corresponding to the steady-state slip: $s=s_{1}$.

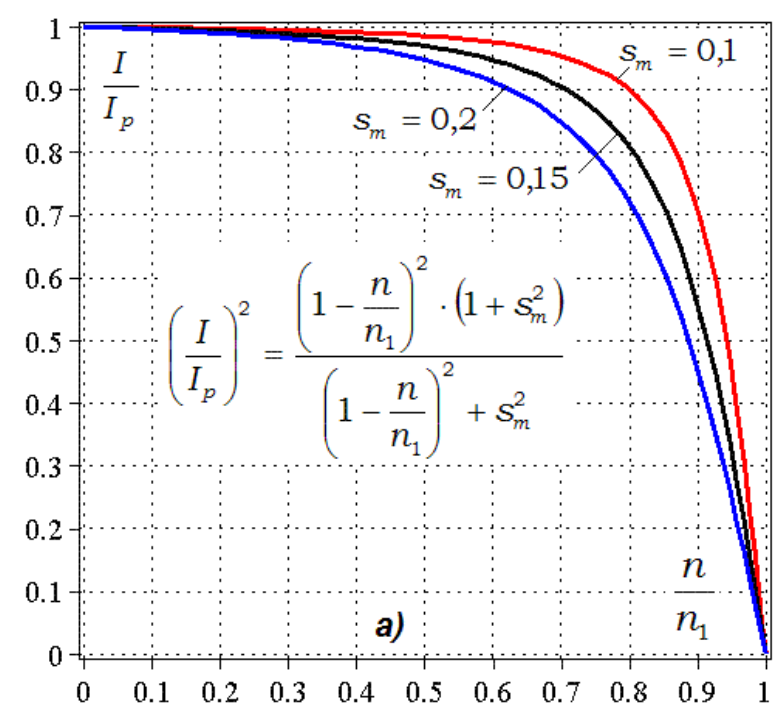

Figure 2-a 


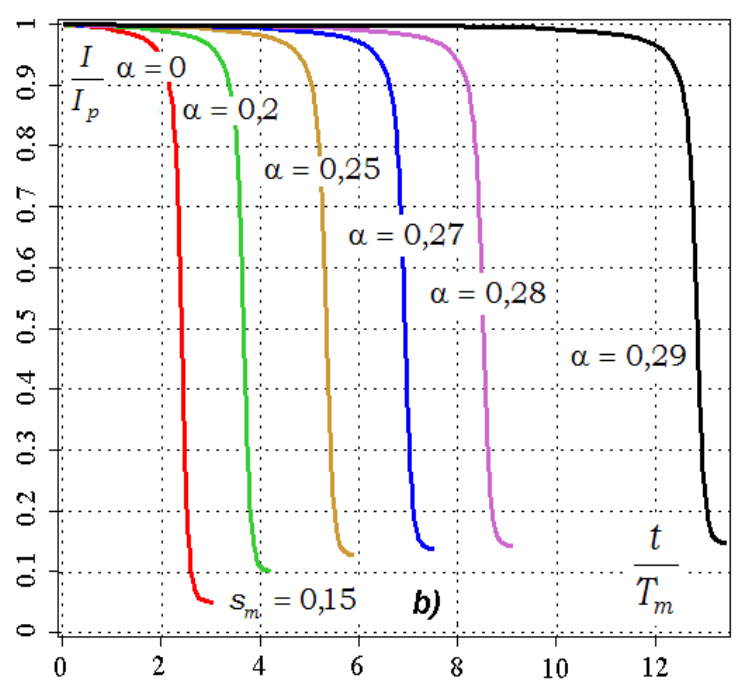

Figure 2-b. The inrush current time variation for different values of critical slips and parameters $\alpha$.

The starting time $t_{s}$, can be expressed in terms of the flywheel assembly engine-clutch-gearbox-driven machine $G d^{2}$ in $\left[\mathrm{kg} \cdot \mathrm{m}^{2}\right]$ and torque acceleration given by the difference between the electromagnetic $M$ and the resistive torque $M_{r}$, respectively. Accordingly on can write [14-17]:

$$
t_{s}=\frac{G d^{2} n_{n}}{375\left(M-M_{r}\right)}
$$

where $M$ and $M_{r}$ are given in [kg.m], speed in [rev./min], and $t_{s}$ is [s].

The above relationship is more a quantitative estimation because both torques are not constant during the start-up process. The starting time depends, therefore, on the motor load i. e. larger the load, longer starting time.

Depending on the duration of the motor start-up, there are: easy start-up $\left(t_{s}<4 \mathrm{~s}\right)$, normal start-up $\left(t_{s} \in 4 \div 10 \mathrm{~s}\right)$ and heavy start-up $\left(t_{s}>10 \mathrm{~s}\right)$ [5-10]. The time variation of the inrush current according to the "difficulty" of starting process is qualitatively represented in Figure 3.

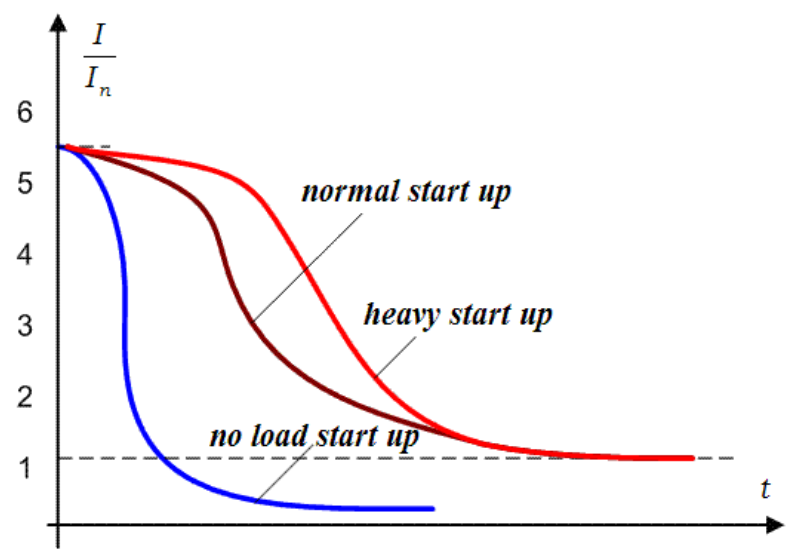

Figure 3. Time variation of the current drawn by the motor for various start-up situations.
Due to the significantly higher inrush currents, a longer start-up process brings additional thermal stress for the motor and network. Supplementary, frequent starts also contribute to the worsening of the thermal state of the motor and to all the electric installation components.

The effective value of an operating induction motor current (or stator current) $I=I_{s}$ is a function of the slip value $s[1-7]$ :

$$
I=I_{s}=U_{1} \frac{\sqrt{1+\left(R_{1}+R_{2}^{\prime} /\left(s X_{m}\right)\right)^{2}}}{\sqrt{\left(R_{1}+R_{2}^{\prime} / s\right)^{2}+\left(X_{1}+X_{2}^{\prime}\right)^{2}}}
$$

where $U_{l}$ is the effective supply voltage, $R_{l}, X_{l}$ and $R_{2}^{\prime}$, $X_{2}^{\prime}$ are stator and respectively rotor resistance and leakage reactance, while $X_{m}$ is the magnetizing reactance [1-5].

The initial value of the starting current, at zero speed or slip $s=1$ (occurring when the rotor is immobile and considering $R_{2}^{\prime} / X_{m}<<1$ ) is called the initial inrush current $I_{p i 0}=I_{p}$ :

$$
I_{p i 0}=I_{p}=\frac{U_{1}}{\sqrt{\left(R_{1}+R_{2}^{\prime}\right)^{2}+\left(X_{1}+X_{2}^{\prime}\right)^{2}}}
$$

The time variation of the motor effective current value immediately after the energizing is qualitatively represented in Figure 4, where the three area of the startup process are indicated along with their corresponding duration $t_{0}$ and $t_{l}$ respectively [10-15].

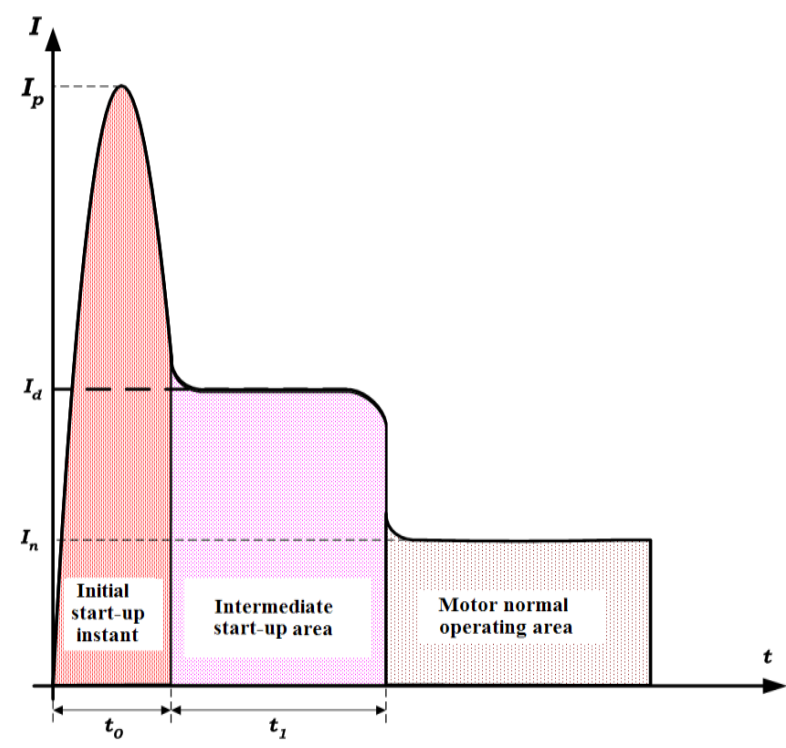

Figure 4. Time variation of the current drawn by the motor during the start-up process. 


\section{THE EXPERIMENTAL RESULTS}

In order to validate the theoretical prediction illustrated in the previous Sections, a low-voltage induction motor of 4 $\mathrm{kW}$ was investigated during start-up process with a power quality analyzer CA 8320 [24]. The whole measurement set-up along with the examined asynchronous motor is illustrated in Figure 5.

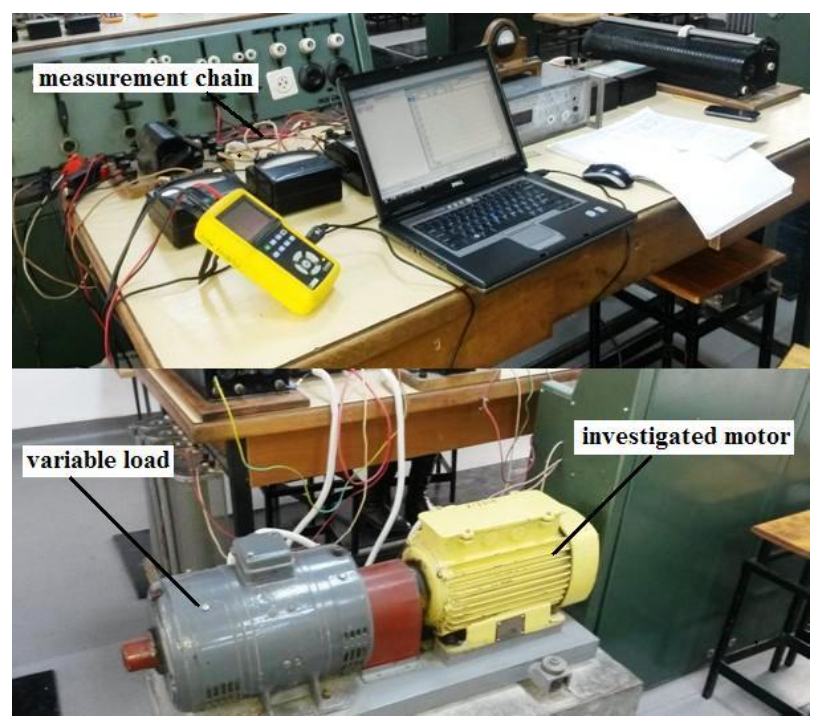

Figure 5. The measuring chain to investigate the starting current of an asynchronous motor of $4 \mathrm{~kW}$.

The measuring chain is able to capture and analyze, due to its dedicated software, the inrush current waveform, its effective value and the current frequency during the whole energizing process. A no-load DC generator is used as working machinery into the drive system. Thus, the main inrush-current characteristics are illustrated in Figure 6, Figure 7 and Figure 8, respectively. The examined motor data are indicated in Appendix.

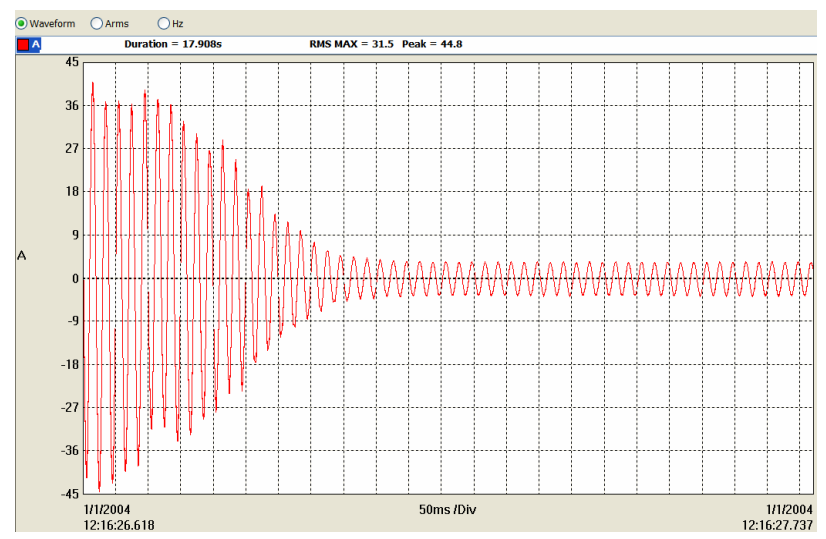

Figure 6. The measured inrush current waveform time variation.

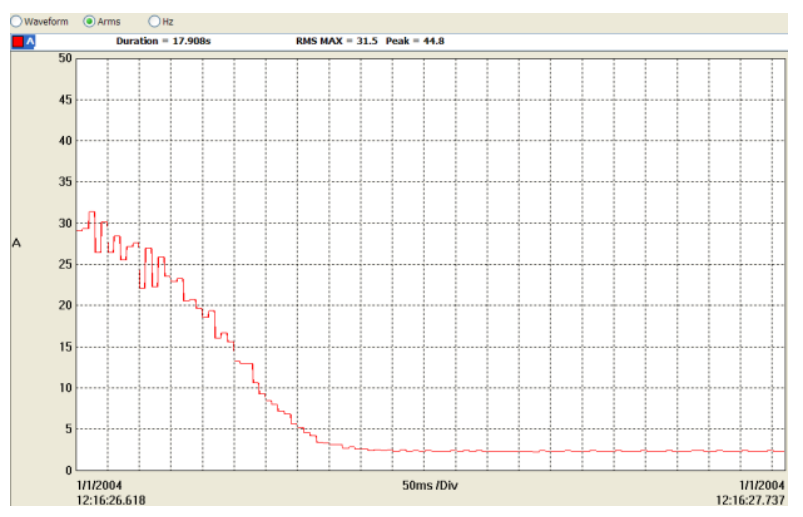

Figure 7. The measured inrush current effective value time variation.

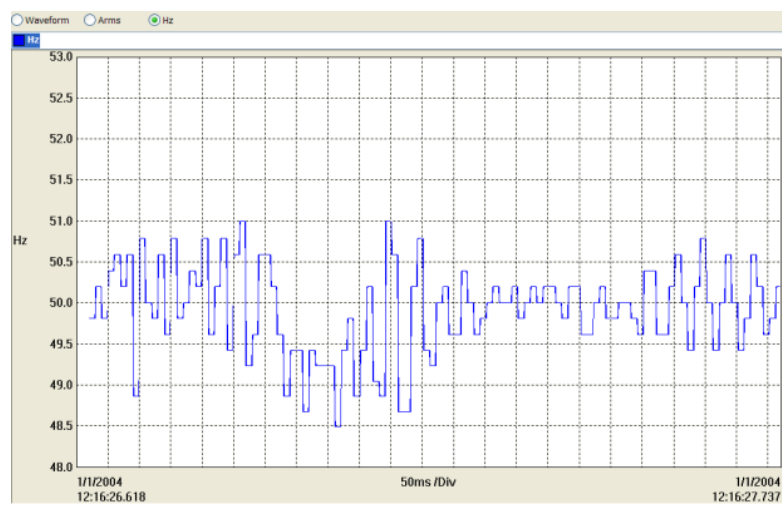

Figure 8. The measured frequency of the current during start-up process.

\section{THE MOTOR INRUSH CURRENT CONTROL}

For motors with higher power units, one may apply, depending on power level the machine and its operating mode, the following classical procedures [1-5]: star-delta starter, rheostat starters, series stator coils, autotransformer starter, or more recently, the usage of static power converters [8-12]. For motors driven by variable-frequency drive, energising is performed implicitly with a voltage-frequency control [9-15].

Often, for squirrel cage motors the starting procedure is performed by an AC voltage controller (ATV), commonly called soft starters, without adjusting the motor rotation speed. Mainly, the latter contain power electronics devices (triacs, thyristors, IGBTs, etc.) which, by adjusting the conduction angle (that can vary between 0 and $\pi$ ), the voltage root mean square applied to the motor can be conveniently change - Figure 9.

The general operating principle of a soft starter is illustrated in Fig. 10-a. The command and control block are set to the maximum starting current, typically $I_{s}=(2 \div 3) I_{n}$. The control of electric current in the circuit is performed by adjusting the conduction angle of the semiconductors elements - Figure 10-b. 


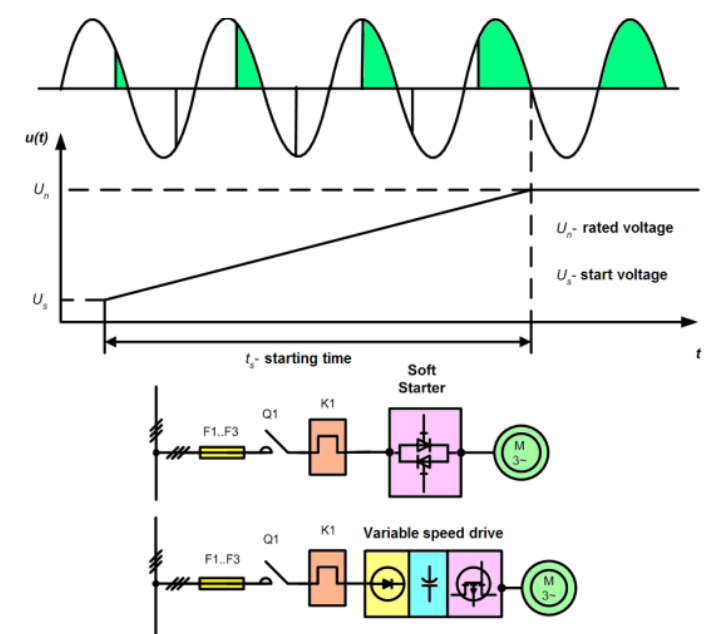

Figure 9. Time variation of the current drawn by the motor for during soft start.

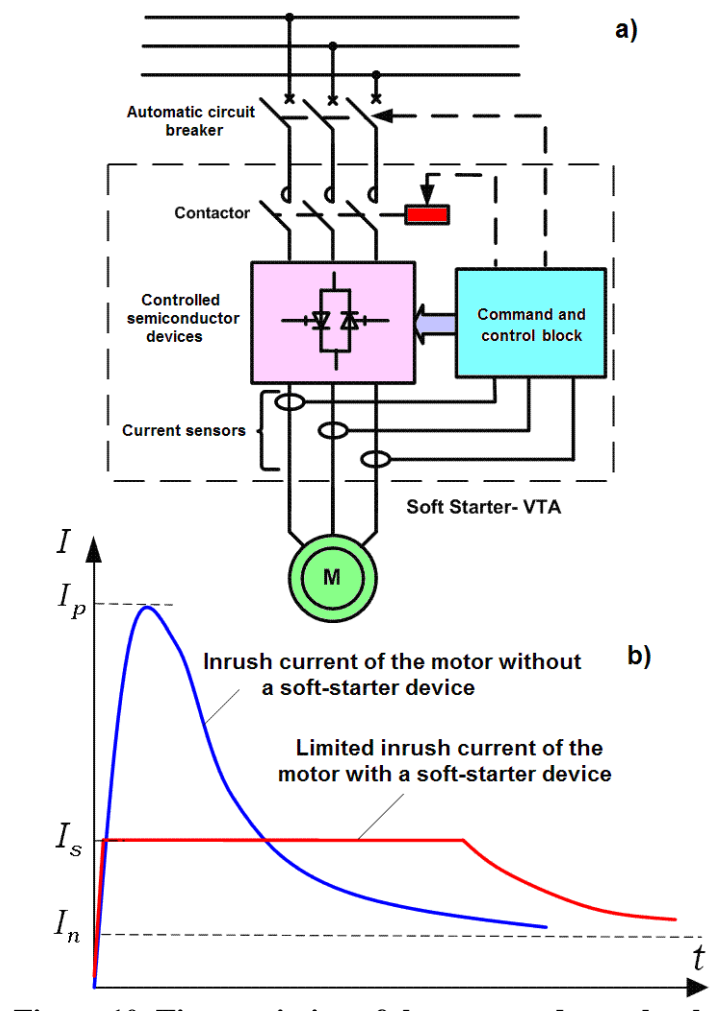

Figure 10. Time variation of the current drawn by the motor for different start-up situations.

\section{DISCUSSIONS AND REMARKS}

For most of the induction motor, the starting current is indicated by the machine manufacturer by the ratio $I_{s} / I_{n}$ (also called the as starting factor $k_{p}$ ). The latter varies as a function of power rate and synchronous speed of the induction motor. Thus, for rated powers above $1.5 \mathrm{~kW}$ and synchronous speeds of 1000, 1500 and 3000 [rev./min], which are the most common, the starting factor lies within the range $5.5 \div 7.5$.

The inrush current amplitude when the motor is directly connected to the power lines $(D O L)$ called also peak inrush current, can even reach values of 2.5 times the actual starting current. The thermal effect of this peak inrush current is negligible because of the very small duration. Compared with that, the electrodynamics effects on the network conductive and nonconductive elements are significant. That could generate unpredictable of triggering of the switching devices having undesirable consequences for the power system. In order to avoid these important mechanical and thermal stresses acting on the machine and the power grid as well, the electric installation regulations restrict the maximal low-voltage three phase motors power that can be started on direct coupling to the network is $5.5 \mathrm{~kW}$ and $4 \mathrm{~kW}$ for singlephase machine. Additionally, the maximum power of the motor that could be directly connected to a network must not exceed $20 \%$ of the transformer rated power that supplies the facility [3-5]. Modern electric industrial drives should provide a large speed control, high starting torque, low power consumption and favourable power quality parameters. Also, lately, a particular interest is dedicated to communication skills of the drive system with a central monitoring, control and diagnostics centre. That enables an easy integration of the drive into so called expert systems in modern industrial facilities [15-23].

A widely used solution for induction motor drives is to supply the motor system with a variable voltage and frequency energy source. This so called scalar control method allows a precise adjustment of energy consumption in the process, avoiding losses in the regulation system of traditional drives. Devices with scalar control of the drive motors are also called converters (inverters) frequency (Variable-Frequency Drive - VFD or Adjustable-Frequency Drive)- Figure 11.

The large usage of the frequency converters for feeding the squirrel cage asynchronous motors leads to the significant disturbances to the mains supply system [25].

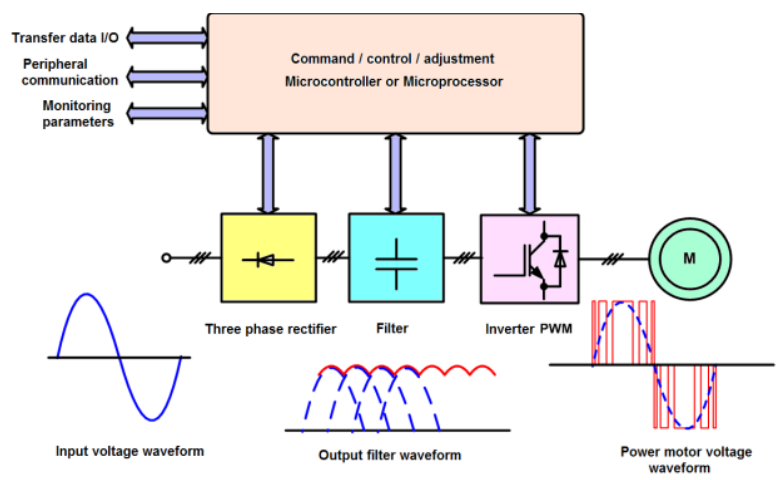

Figure 11. The principle of the adjustable-frequency drive.

These low power quality issues consist in current and even voltage harmonics and interharmonics (in network with high internal impedance). To mitigate the adverse effects of harmonics injections into the network one may use different types of filters. The latter are designed according to the dominant harmonic attendance into the waveform of voltage or current spectrum respectively.

To obtain an outstanding dynamic performance and high energy efficiency of electric drive systems a vectorial control method was adopted (Motor Vector Control). This particular drive mode requires a magnetic flux oriented 
control of the machine (FOC - Field Oriented Control) or more recently, a direct torque control $(D T C$ - Direct Torque Control). These methods ask for the usage of relatively new sensors, which should precisely measure different control parameters collected from the operating motor - Figure 12. There are also new versions of motor vector control without sensors (sensorless), with the disadvantage of a lower accuracy and higher costs [2-5].

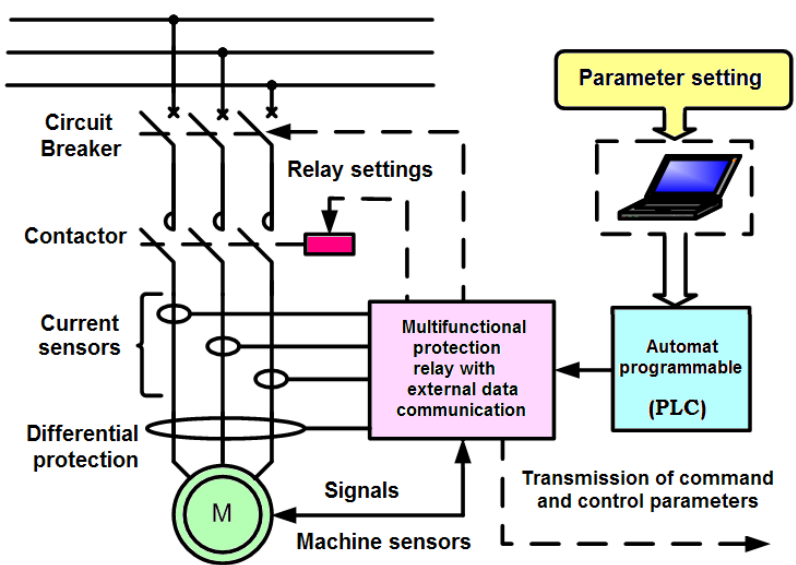

Figure 12. The principle of motor speed vector control.

The latest quite spectacular results the area of automated electric drive motors (not only the induction machines) was possible due to significant growth in the last decades of the power electronics (components and static converters with outstanding performance), the progress in the adjustment and automatic control theory, applied informatics and communications techniques [25, 26].

\section{CONCLUSIONS}

The paper investigates both theoretically and experimentally the energizing process of low-voltage induction motors from actual industrial electrical installations. The analysis was conducted in order to estimate the starting time of the motor by considering the machine rated data and the mechanical characteristics of the drive system that incorporates the motor. The starting process is mathematically modeled by a differential equation system whose solutions determinate the dynamical characteristic of this transient state. The parameterization of different starting parameters such speed or effective current value was also carried out, revealing important dependencies of the energizing parameters. These could be very useful for establishing the machine adaptability to a certain electric drive requirement. The inrush current features of a $4 \mathrm{~kW}$ induction motor were measured in order to illustrate the theoretical assumptions. Supplementary, a critical overview of the most common and actual starting procedure was examined, highlighting their performances and drawbacks. The motor energizing quantitative investigation is to be improved in terms of its accuracy by considering also the losses (especially the magnetic losses) within the machinery during the starting process.

\section{APPENDIX}

The main parameters of the inspected asynchronous motor are presented in Table 1.

Table 1. The investigated motor rated parameters

\begin{tabular}{|l|c|}
\hline Motor data & Value \\
\hline Rated power: $P_{n}$ & $4 \mathrm{KW}$ \\
\hline Pole pair number: $p$ & 1 \\
\hline Rated frequency: $f_{n}$ & $50 \mathrm{~Hz}$ \\
\hline Rated voltage: $U_{n}$ & $230 \mathrm{~V}$ \\
\hline Rated speed: $n_{n}$ & 1498 [r.p.m.] \\
\hline Rated efficiency: $\eta_{n}$ & 0.75 \\
\hline Rated power factor $\mathrm{PF}_{\mathrm{n}}\left(\cos \varphi_{n}\right)$ & 0.85 \\
\hline
\end{tabular}

\section{ACKNOWLEDGMENTS}

This work was supported by a grant of the Romanian National Authority for Scientific Research and Innovation, CNCS/CCCDI-UEFISCDI, project no. PNIII-P2.-2.1-PED-2016-0451, within PNCDI III.

\section{REFERENCES}

[1] Chapman, S., Electric Machinery Fundamentals, Mcgraw Hill Higher Education; 5 ${ }^{\text {th }}$ Edition, 2011.

[2] Krause, P. C. et al., Analysis of Electric Machinery and Drive Systems, Wiley-IEEE Press, $3^{\text {rd }}$ edition, 2013.

[3] Bose, B. K., Power Electronics and Motor Drives: Advances and Trends, Academic Press, 1st Edition, 2006.

[4] Schonek, J., Nebon, Y., LV protection devices and variable speed drives (frequency converters), Schneider Electric, Cahier Technique no. 204, 2002.

[5] Clenet, D., Electronic starters and variable speed drives, Schneider Electric, Cahier Technique no. 208, 2003.

[6] Bruce, F. M., Graefe, R. J., Lutz, A. \& Panlener, M. D., Reduced-Voltage Starting of Squirrel-Cage Induction Motors. IEEE Transactions on Industry Applications, Vol. IA- 20, No. 1, pp. 46-55, January/February 1984.

[7] Baurand, G., Moliton, V., The protection of $L V$ motors, Schneider Electric, Cahier Technique no. 211, 2007.

[8] Nevelsteen, J. \& Aragon, H., Starting of Large Motors - Methods and Economics, IEEE Transactions on Industry Applications, Vol. 25, No. 6, pp. 1012-1018, November/December 1989.

[9] E. Cazacu and L. Petrescu, Magnetizing inrush current of low-voltage iron core three phase power reactors, $16^{\text {th }}$ International Conference on Harmonics and Quality of Power (ICHQP), Bucharest, pp. 843-847, 2014.

[10] E. Cazacu, V. Ioniţă, L. Petrescu, Numerical and experimental investigations on the energizing of miniature iron core transformers, $9^{\text {th }}$ International Symposium on Advanced Topics in Electrical Engineering (ATEE), Bucharest, pp. 170-175, 2015. 
[11] E. Cazacu, V. Ioniţă, L. Petrescu, An improved method for the inrush current evaluation in single phase power transformers, $8^{\text {th }}$ International Symposium on Advanced Topics in Electrical Engineering (ATEE), Bucharest, pp. 1-6, 2013.

[12] E. Cazacu, V. Ioniţă, L. Petrescu, An efficient method for investigating the ferroresonance of single-phase iron core devices, $10^{\text {th }}$ International Symposium on Advanced Topics in Electrical Engineering (ATEE), Bucharest, pp. 363-368, 2017

[13] Nied, A.; Dias, R. P.; de Oliveira, J.; Campos, R. de F \& Marques, L. C. de S., Soft Starting of Induction Motor with Torque Control, Proceedings of Industry Applications Society Annual Meeting, Edmonton, Canada, 2008.

[14] Cazacu E., Instalaţii electrice moderne (in Romanian), Editura Matrix-Rom, 2016.

[15] Cazacu E., Petrescu L., Expertiza sistemelor electrice industriale (in Romanian), Editura Printech, 2014.

[16] Holtz, J., Drift-and Parameter-Compensated Flux Estimator for Persistent Zero-Stator-Frequency Operation of Sensorless-Controlled Induction Motors. IEEE Transactions on Industry Applications, vol. 39, No. 4, pp. 1052-1060, July/August 2003.

[17] Nied, A.; de Oliveira, J.; de Farias Campos, R.; Dias, R. P., Soft Starting of Induction Motor with Torque Control, IEEE Transactions on Industry Applications, Vol. 46, No. 3, (May/June 2010), pp. 1002-1010, 2010.

[18] Colleran, P. J. \& Rogers, W. E., Controlled Starting of AC Induction Motors, IEEE Transactions on Industry Applications, Vol. IA-19, No. 6, pp. 10141018, November/December 1983.

[19] Xu, X. \& Novotny, D. W., Implementation of Direct Stator Flux Orientation Control on a Versatile DSP Based System. IEEE Transactions on Industry Applications, Vol. 27, No. 4, pp. 694-700, July/August 1991.

[20] Zenginobuz, G.; Cadirci, I.; Ermis, M. \& Barlak, C., Soft-Starting of Large Induction Motors at Constant Current with Minimized Starting Torque Pulsations, IEEE Transactions on Industry Applications, Vol. 37, No. 5, pp. 1334-1347, September/October 2001.

[21] P. Aree, Starting time calculation of large induction motors using their manufacturer technical data, $201619^{\text {th }}$ International Conference on Electrical Machines and Systems (ICEMS), Chiba, 2016, pp. $1-5$.

[22] E. K. Mohammedsaeed, A. A. Karrar, Finite element method based design of a Liquid Rheostat motor starter, Power Electronics Drives and Energy Systems (PEDES) 2016 IEEE International Conference on, pp. 1-6, 2016.

[23] Gaucheron, E. Electric motors ... and how to improve their control and protection, Schneider Electric, Cahier Technique no. 207, 2004.

[24] *** C.A 8230 - Single Phase Power Analyzer, Chauvin Arnoux Corporation, 2008.
[25] Rashid, H. M., Power Electronics: Circuits, Devices \& Applications, Prentice Hall, $4^{\text {th }}$ Ed., 2013.

[26] ABB - Technical Application Papers - Vol. 7Three-phase asynchronous motors - generalities and ABB proposals for coordination of protective devices, 2008. 